\title{
O colonialismo em África e seus legados: classificação e poder no ordenamento da vida social
}

Colonialism in Africa and its legacy: classification and power in the framing of social life

Wilson Trajano Filho e Juliana Braz Dias

\section{(2) OpenEdition}

Edição electrónica

URL: https://journals.openedition.org/aa/1371

DOI: $10.4000 /$ aa. 1371

ISSN: 2357-738X

Editora

Programa de Pós-Graduação em Antropologia Social (UnB)

Edição impressa

Data de publição: 1 dezembro 2015

Paginação: 9-22

ISSN: 0102-4302

Refêrencia eletrónica

Wilson Trajano Filho e Juliana Braz Dias, «O colonialismo em África e seus legados: classificação e poder no ordenamento da vida social», Anuário Antropológico [Online], v.40 n.2 | 2015, posto online no dia 01 junho 2018, consultado o 21 setembro 2021. URL: http://journals.openedition.org/aa/1371 ; DOI: https://doi.org/10.4000/aa.1371

\section{(c) $(1)(9)$}

Anuário Antropológico is licensed under a Creative Commons Atribuição-Uso Não-Comercial-Proibição de realização de Obras Derivadas 4.0 International. 


\title{
O colonialismo em África e seus legados: classificação e poder no ordenamento da vida social
}

\author{
Wilson Trajano Filho \\ $\mathrm{UnB}$ \\ Juliana Braz Dias \\ UnB
}

O colonialismo foi mais do que um sistema de exploração econômica e de dominação política, podendo mesmo ser entendido como um modo de percepção do mundo e de enquadramento da vida social. Este número especial do Anuário Antropológico discute as categorias geradas pelo colonialismo. Reunindo pesquisas cujo enfoque recai sobre as experiências coloniais em África, as contribuiçóes agregadas neste volume analisam os mapas mentais elaborados por uma variedade de sujeitos no intuito de orientar a navegaçáo na paisagem colonial africana. Igualmente, fornecem subsídios para uma reflexão crítica sobre o que restou desse modo de enquadrar o mundo depois das descolonizaçóes.

Os estudos históricos sobre a presença europeia em África, bem como os eventos contemporâneos que recorrentemente descortinam aos olhos do mundo as feridas abertas deixadas naquele continente pelos projetos imperialistas, não permitem minimizar a violência explícita das açóes de subjugação política e de extração de recursos que acompanharam o colonialismo. $\mathrm{O}$ que os estudos coloniais e pós-coloniais têm demonstrado, porém, sobretudo aqueles realizados a partir da década de 1990, é que tais dimensóes dos projetos imperialistas devem ser vislumbradas através de uma nova lente (ver, especialmente, Comaroff \& Comaroff, 1991, 1997; Cooper \& Stoler, 1997a). Num sentido mais amplo, o colonialismo passa a ser entendido como um evento que alcançou os domínios mais insólitos das práticas cotidianas, os mais recônditos cantos da vida social. Como produto de um complexo encontro que alterou a tudo e a todos (Comaroff \& Comaroff, 1997), trata-se de "um processo histórico totalizante, instituidor de uma hegemonia orientadora da percepção e da experiência social" (Trajano Filho, 2004:23).

Em outras palavras, o esforço conjunto da historiografia e da antropologia realizado nas últimas décadas tem levado a um exame do colonialismo como um processo que atuou, "simultaneamente, igualmente e inseparavelmente", na economia política e na cultura (Comaroff \& Comaroff, 1997:19). Economia política e cultura são, portanto, aspectos de uma mesma realidade. O colonialismo está 
relacionado ao evento histórico do capitalismo industrial e aos imperativos materiais da modernidade, ao mesmo tempo que atravessa o campo das representaçóes, dos discursos e dos valores. Como tal, foi experienciado, pela pluralidade de sujeitos envolvidos, na totalidade da vida social e na própria definição dos termos em que essa realidade se apresentava à experiência, classificando-a e hierarquizando-a.

\section{Classificaçáo e poder nas experiências coloniais}

Nothing should be named lest by so doing we change it.

Virginia Woolf

A construção de sistemas classificatórios não é uma preocupação nova na antropologia, ocupando o coração da disciplina desde seus primórdios. Em 1903, na obra De quelques formes primitives de classification: contribution à l'étude des représentations collectives, Durkheim e Mauss já indicavam a importância da função classificatória na vida social. Seja no totemismo australiano, seja nas taxonomias de cunho científico - exemplos paradigmáticos do primitivo e do moderno, no pensamento dos autores —, encontramos sempre um esforço de construção de "sistemas de noçóes hierarquizadas", nos quais as coisas encontram-se dispostas em grupos que mantêm relaçôes definidas uns com os outros, formando um todo no seu conjunto (Durkheim \& Mauss, 1981:197). Estamos diante da universalidade dos "hábitos mentais em virtude dos quais concebemos os seres e os fatos sob a forma de grupos coordenados e subordinados uns aos outros" (Durkheim \& Mauss, 1981:203).

Criar categorias é, portanto, uma atividade humana fundamental. E, por ser uma forma de ordenar o mundo e moldar a percepção sobre ele, é também um ato de poder. Nomear, classificar, construir relaçôes entre categorias são todas formas de criação de uma realidade que se propóe absoluta, ainda que precise conviver com percepçôes concorrentes. Eis aí o espírito dos projetos imperialistas em África. Os regimes coloniais representaram empreendimentos grandiosos direcionados a instaurar uma visão de mundo singular, buscando estratégias de imposição de um conjunto de categorias e valores que classificavam as pessoas e as coisas, construindo hierarquias e fornecendo, assim, as bases sobre as quais se sustentavam as práticas de dominação.

Nos regimes coloniais, muita energia foi investida na construção de categorias sociais - particularmente, na definição da dicotomia fundamental entre colonizador e colonizado. Essas duas classes em oposição tiveram que ser cuidadosamente fabricadas. Como apontam Cooper e Stoler (1997b:3-4), uma 
gramática da diferença precisava ser continuamente construída para a legitimação dos impérios. O sucesso do empreendimento colonial dependia da criação e manutenção de uma percepção do mundo fundada em relaçóes de identidade e alteridade, devidamente valoradas. Era preciso definir o status de cada pessoa na nova estrutura forjada pelo colonialismo.

A realidade com que lidavam os agentes do poder colonial era extremamente plural e com contornos pouco definidos. Em primeiro lugar, as sociedades que os europeus encontraram em África eram muito diversificadas. Em segundo lugar, a própria categoria "europeu" abarcava uma multiplicidade de atores, entre administradores, missionários, colonos, homens de negócio e militares, com agendas díspares e relaçóes conflituosas - todos eles pertencentes a impérios coloniais muito desiguais entre si. Por fim, estavam todos envolvidos em situaçóes de encontros intersocietários marcados por trânsitos de naturezas diversas. Os contatos e as trocas que os acompanhavam davam origem a uma dinâmica social complexa, produtora de hibridismos, misturas, apropriaçóes e aproximaçóes. Em virtude disso, categorias como "civilizado", "assimilado", "moderno" e "tradicional" foram criadas para simplificar, distinguir e hierarquizar. Quanto menos claras as fronteiras, mais a administração colonial investia na reinvenção e imposição de sistemas classificatórios:

uma grande burocracia colonial ocupou-se, especialmente a partir da década de 1860, com a classificação de pessoas e de seus atributos, com censos, surveys e etnografias, com o registro de transações, a delimitação de espaços, o estabelecimento de rotinas e a padronização de práticas. $\mathrm{O}$ efeito total excedeu a soma de cada apropriação de informação: os regimes coloniais estavam tentando definir os elementos constituidores de um certo tipo de sociedade, ainda que eles incorporassem aquele ato de criação numa noção de que a sociedade era um fato natural e de que o Estado era um regulador apartidário e um observador neutro (Cooper \& Stoler, 1997b:11).

Investiam, assim, na categorização das pessoas e na definição e naturalização de novas unidades sociais. A própria ideia de "África" foi um instrumento de homogeneização e essencialização útil para as definiçôes dos impérios (Cooper \& Stoler, 1997b). A África era o "outro" a partir do qual a ideia de Europa se consolidava. Mais do que representar a divisão entre dois continentes, o termo implicava a divisão entre duas classes de pessoas: europeus e africanos, colonizadores e colonizados.

Duas observaçóes precisam ser feitas para o desenvolvimento das discussóes que atravessam este dossiê. Primeiramente, é preciso insistir no caráter totalizador desses sistemas classificatórios. Ou seja, a dicotomia central - colonizador versus 
colonizado - desdobra-se, percorrendo múltiplas dimensôes da vida social. Categorias jurídicas que condicionavam o acesso a direitos políticos e civis dos sujeitos coloniais foram articuladas a outras tantas classificaçôes: religiosa, estética, territorial, comportamental etc. O estudo da vida colonial precisa, então, abrir-se ao exame de novos terrenos, como a linguagem, os atos de sociabilidade, a vida doméstica, os rumores e as variadas formas de manifestaçáo artística. O conjunto desses campos nos fornece elementos para uma apreciação mais acurada do que foram as experiências nascidas desse encontro transformador em território africano.

Em segundo lugar, tem se mostrado produtivo o entendimento do colonialismo como uma forma de hegemonia, sob uma ótica gramsciana. Queremos dizer com isso que ele não se restringiu às formas de poder mantidas diretamente pela agência dos grupos sociais dominantes, cuja atuação se dava no nível da consciência, tanto dos dominantes quanto dos subordinados (Williams, 1979). Como um poder hegemônico, o colonialismo atuou igualmente de forma mais difusa e indireta. De acordo com Comaroff e Comaroff (1991), trata-se de um poder que prolifera fora do domínio da política institucionalizada e que acaba sendo internalizado, na forma de convençóes e valores. Sugere-se assim que, nas próprias sociedades coloniais, a lógica dualista instaurada pelo colonialismo frequentemente se solidificava, reproduzindo dado ordenamento social que simplificava uma realidade muito mais complexa. O regime colonial "sustentou uma gramática de distinçóes que se inseriu no mundo dos colonizados, entrando nas suas próprias autoconstruçóes e afetando os modos como eles incorporaram suas identidades" (Comaroff \& Comaroff, 1997:25).

Por outro lado, importa ressaltar que, embora dominante, a hegemonia jamais será exclusiva (Williams, 1979). Ela também apresenta fragilidades e precisa responder a uma série de pressóes exercidas por outros campos de força que a limitam. No caso em questão, abrimos espaço para pensar, ao lado da internalização da visáo de mundo imposta pelo colonialismo, formas de resistência ao regime: da caricatura mordaz dos agentes de poder colonial (Ranger, 1968a, 1968b) e dos movimentos de revitalização religiosa (Fabian, 1971) à resistência armada. No contexto colonial, portanto, "[o]s europeus foram permanentemente desafiados, seja pela oposição frontal e violenta, seja pelas armas típicas dos fracos como a sabotagem, dissimulação, deserção, calúnia, pequenos furtos e rumores" (Trajano Filho, 2006:12). E para além da discussáo sobre resistência, que sozinha não nos permite escapar das amarras das dicotomias, é preciso estar atentos a outras tantas formas de agência dos "dominados", mais sutis e ambíguas, fundadas em processos de negociação e geradas na própria dinâmica dos encontros coloniais (Trajano Filho, 2006). 


\section{(Des)continuidades no mundo pós-colonial}

Outra questão que se coloca diante do quadro aqui apresentado diz respeito ao que acontece atualmente nos contextos pós-coloniais. Como as categorias do colonialismo e sua lógica de exclusões e inclusões se revelam no mundo contemporâneo? Nos artigos deste volume, percorremos várias trilhas abertas em meio a uma flora abundante de dados que nos levam a pensar sobre a persistência da história (Carvalho \& Pina Cabral, 2004). Os trabalhos aqui apresentados estão ancorados em uma variedade de fontes, que vão da profusão de material de arquivo - nas suas várias formas, exploradas por quase todos os autores - às artes literárias, chegando à etnografia, método antropológico por excelência que vem acrescentar a este diálogo interdisciplinar com a história.

São veredas que percorrem vastas regiôes do continente africano, passando por Moçambique (Albert Farré), África do Sul (Laura Moutinho), Namíbia (Josué Tomasini Castro e Eduard Gargallo), Angola (Carla Susana Alem Abrantes) e Casamansa senegalesa (Jordi Tomàs), alcançando também as ilhas de Cabo Verde (Celeste Fortes e Andréa Lobo) e São Tomé e Príncipe (Gerhard Seibert). Atravessam também diferentes contextos históricos: dos primeiros encontros (Lobo) e dos tempos do colonialismo - antigo e tardio (Abrantes, Castro, Farré, Gargallo, Lobo, Seibert e Tomàs) — ao mundo pós-colonial (Farré, Fortes, Lobo, Moutinho e Seibert).

O que descobrimos ao longo dessa caminhada é que categorias e valores têm sido reproduzidos, às vezes ligeiramente modificados. A continuidade de alguns aspectos do modo colonial de organizar a vida social justifica-se pela força hegemônica do mapa mental obsessivamente construído pelas mãos dos agentes do colonialismo, mas também pelos usos estratégicos que tais classificações ainda podem ter para alguns grupos sociais na contemporaneidade. Exemplo disso é apresentado por Lobo ao revelar como as representaçóes da paisagem no Estado cabo-verdiano moderno redesenham as antigas imagens coloniais de uma natureza hostil, agora instrumental na atração de capital dos doadores internacionais. A reprodução de categorias sociais originadas nos regimes coloniais pode ser encontrada em diferentes contextos: de persistentes representaçóes raciais a formas contemporâneas de classificação e hierarquização de hábitos, relaçóes, espaços, conhecimentos, línguas, crenças religiosas, sistemas políticos, moralidades etc.

O colonialismo, porém — como já destacado —, não reinou soberano sobre as mentes dos sujeitos. Os artigos aqui agregados também nos revelam as facetas mais frágeis dos regimes coloniais ao longo do tempo. $\mathrm{O}$ que chamamos apressadamente de política colonial congregou, de fato, uma pluralidade de discursos e práticas, muitas vezes inconsistentes e contraditórios. A esse respeito, 
podemos ver os diferentes discursos coloniais relativos às comunidades San da África Austral, apresentados por Gargallo, bem como as imagens contrastantes construídas pelos franceses sobre a sociedade joola do Baixo Casamansa, descritas por Tomàs.

Os regimes coloniais precisaram lidar também com a inconstância das relaçóes sobre as quais se assentavam. As experiências coloniais estiveram imbricadas numa realidade altamente dinâmica. Ilustrativo, nesse sentido, é o caso de São Tomé e Príncipe, apresentado por Seibert. O autor mostra, por exemplo, como as políticas de incentivo ou refreamento da miscigenaçáo variaram conforme o contexto histórico, de acordo com o maior ou menor interesse local no processo de crioulização e na geração de categorias intermediárias.

Mesmo quando relativamente bem estruturadas, as políticas coloniais precisavam lidar com os desafios reais das condiçôes locais, que significavam muitas vezes um esforço continuado para a manutenção da vida em situaçôes adversas - como os constrangimentos impostos pelo meio ambiente (Castro e Lobo) e pela escassez de recursos materiais (Fortes), constrangimentos estes que ainda apresentam relativo impacto na contemporaneidade.

Por fim, os regimes coloniais precisaram dialogar continuamente com a agência dos "colonizados". Nesse encontro intersocietário, também os indígenas avaliavam e classificavam o outro, seus hábitos e conhecimentos, e organizavam açôes de resistência (ver o caso joola, analisado por Tomàs). E, para além de mera resposta à opressão colonial, o idioma indígena nunca deixou de revelar seu caráter ativo na conformação das identidades e das experiências coloniais em geral (Castro). É a mesma tônica da agência que encontramos no mundo pós-colonial e nas diversas formas acionadas pelos sujeitos no processamento das heranças do colonialismo.

\section{Pluralidade temática}

Uma característica do conjunto de textos reunidos neste dossiê é a capacidade de atravessar um espectro amplo de temáticas. Alinhavados por uma questáo central, os argumentos percorrem diversos tipos de categorizaçóes produzidas pelos regimes coloniais. A classificação e hierarquização de pessoas é, certamente, um mote trabalhado por todos os autores que contribuem para o volume. Mas eles se aventuram ainda por outros sistemas classificatórios, que ordenam os espaços (Castro, Gargallo e Lobo), as crenças religiosas (Farré, Gargallo, Moutinho, Seibert e Tomàs), os sistemas políticos e jurídicos (Farré, Gargallo e Tomàs), os regimes de trabalho (Abrantes, Farré e Seibert), as línguas (Farré, Gargallo e Seibert) e as formas de organização familiar (Fortes). 
Como esse esforço não se pretende conclusivo, outras temáticas ficam ainda por abordar. Parece muito promissora, por exemplo, uma investigação dos universos tradicionalmente subestimados do colonialismo: as esferas das maneiras, da etiqueta e da higiene. Tal via, focada na experiência mais microscópica das vidas das pessoas e dos grupos nas colônias e na sua percepçáo do mundo cotidiano, pode facilitar o acesso ao campo mais amplo de controle e dominação das pulsóes que conhecemos como processo civilizador.

As línguas merecem certamente mais do que breve menção, constituindo um campo riquíssimo para o exame dos processos de construção de diferenças no mundo colonial. Quando Gargallo nos apresenta o dado de que os holandeses consideravam os San escassamente humanos e "sem uma língua propriamente dita", já que "se comunicavam através de sons unicamente", somos levados a pensar nos efeitos dessas representaçóes na atualidade, quando os conceitos de "língua" e "dialeto" são tomados de empréstimo da linguística (e transformados) para, no senso comum, hierarquizar sistemas de linguagem que representam "nós" e os "outros". Numa discussão sobre a persistência da história, mostramse também profícuas as análises dos processos recentes de oficialização de línguas locais (crioulas ou não) na construção dos Estados modernos em África (Braz Dias, 2002).

$\mathrm{O}$ universo das artes nos parece igualmente promissor, especialmente quando atentamos às reproduçôes das categorias coloniais nas formas de circulação e consumo das produçôes artísticas "africanas" em contextos ocidentais. Sally Price (2000) já retratou as marcas do passado colonial na constituição do mercado de "arte primitiva" no Ocidente, carregado de valores na representação do "outro". A criação de um gênero musical denominado world music, responsável por abarcar o conjunto heterogêneo de produçôes musicais não ocidentais, é outro claro exemplo da continuidade dos sistemas classificatórios gerados no colonialismo (Braz Dias, 2012; Erlmann, 1999; Frith, 2000; Stokes, 2004; Taylor, 1997). Tendo em vista a agenda de investigaçóes aqui proposta, são todos temas que merecem maior investimento.

\section{O dossiê em suas partes}

Josué Tomasini Castro abre o conjunto de artigos deste volume, focalizando a experiência das populaçóes herero da Namíbia num período que cobre mais de um século. $\mathrm{O}$ autor argumenta que, apesar da centralidade da dominação colonial na constituição das formas de identificação política, tanto na versão alemã quanto sob o domínio sul-africano marcado pelo regime do apartheid, a experiência dos grupos herero que viviam nas reservas nativas foi mais complexa e ativa do que 
uma mera resposta ou oposição ao domínio colonial. Castro nos mostra que a autoimagem dos grupos herero e o ativismo político de suas lideranças foi, sobretudo, uma resposta aos desafios concretos que eles defrontaram ao viver num território que, por sua ecologia e carência de recursos hídricos, era desfavorável à reprodução social desse povo pastoril.

A contribuição de Gargallo também tem a Namíbia como cenário. Além de uma paisagem geral comum, os dois trabalhos focalizam um mesmo fluxo temporal, que vai da consolidação dos regimes coloniais no final do século XIX ao período pós-independência. Gargallo analisa a importância da visão colonial sobre as populaçóes San da Namíbia e seu impacto nas políticas implementadas pelas administraçóes alemã e sul-africana no território namibiano. Mostra, também, como esse olhar foi em parte incorporado e adaptado por outros grupos africanos e como tem influenciado as políticas na Namíbia independente. A análise centrase nas políticas fundiárias dos governos coloniais e no período pós-independência, mostrando que elas têm alocado e reconhecido aos San apenas pequenas áreas. Por fim, aponta, em linhas semelhantes às notadas por Tomàs sobre os joolas da Casamansa senegalesa, que o olhar colonial sobre os San, frequentemente negativo e cheio de estereótipos, não era homogêneo nem fixo; mostra, ainda, como tal olhar foi adotado pelos africanos da Namíbia, perdurando até o presente.

Saindo da Namíbia, mas continuando no contexto político e na paisagem cosmológica a ela associados, o do apartheid e das respostas contemporâneas a ele, Moutinho, num belo e corajoso texto, explora com refinamento o idioma, ou melhor, o simbolismo com o qual se constrói a biografia de um conhecido líder nacionalista africânder que lutou contra o fim do apartheid na África do Sul. Ela mostra que a biografia Eugène Terre'Blanche - my side of the story pretende ser tanto um testemunho quanto um retrato de e para dos africânderes - um povo que historicamente tem sido visto como o ator central de um abjeto sistema de opressão e dominação e que contemporaneamente se vê ameaçado em sua identidade e liberdade. Ao analisar tal narrativa biográfica, a autora foca com sensibilidade os usos e significados, tanto políticos quanto éticos, das ideias de tragédia e sofrimento, procurando compreender o complexo cenário sociocultural que se coloca contra os direitos humanos, mas que, de um modo profundamente ambivalente, retém um particular sentido de humano. Moutinho nos mostra que a paisagem política e cosmológica da África do Sul contemporânea é desenhada tendo as ideias de raça, religião, gênero e militarismo como os elementos constituidores das diferenças.

O regime colonial português é tema da maioria dos trabalhos deste dossiê. Os artigos de Seibert, Lobo e Fortes tratam das colônias insulares — São Tomé 
e Príncipe e Cabo Verde. Conforme aponta Seibert, trata-se de uma experiência distinta daquela das colônias continentais por três razóes. Primeiramente, porque as ilhas eram territórios desabitados, que foram povoados por gente que veio de fora. Em segundo lugar, por ter se constituído uma formação social sui generis, diferente da minoria europeia que ali se fixou e da maioria de africanos que para lá foi levada em situação de subordinação. Chamamos a isso sociedade crioula. E, finalmente, por representar uma experiência colonial muito mais profunda do que a dos outros casos examinados neste volume.

Seibert focaliza o processo que deu origem à sociedade crioula de São Tomé, ressaltando as peculiaridades das duas fases da colonização: a primeira, que se seguiu à descoberta no final do século XV, perdurando até o início do século XVII; a segunda, tendo início em meados do século XIX, depois de uma hibernação de mais de dois séculos durante os quais a crioulização se consolidou, até ser perturbada por uma nova leva colonial que durou até meados da década de 1970. Além de tratar dos contornos históricos da experiência colonial em São Tomé, Seibert esboça as linhas gerais do momento pós-colonial, deixando entrever as continuidades e as mudanças ocorridas durante esse processo.

A contribuição de Lobo aborda as classificaçôes e percepções culturais sobre a paisagem em Cabo Verde e as relaciona ao processo de colonização. Assim como a de Seibert, a perspectiva da autora tem grande profundidade temporal. Lobo analisa o modo como os portugueses desenvolveram uma visão sobre a paisagem natural das ilhas no momento de sua descoberta, em meados do século $\mathrm{XV}$, e indaga como as representaçôes do ambiente e as formas de classificação da paisagem influenciaram a formação da sociedade cabo-verdiana nos seus primórdios. Após percorrer vários momentos históricos, ela examina as formas como o cabo-verdiano do presente se relaciona com o ambiente físico das ilhas. Sua análise das representaçóes da paisagem enquadra-se numa moldura teórica que toma os modos de relacionamento e domesticaçáo da natureza como um processo de longa duração, afetando tanto os colonizadores quanto os colonizados. E o faz com tal complexidade que torna as explicaçôes polarizadas pela dicotomia dominação e resistência um tanto inadequadas.

Tendo ainda como foco o contexto cabo-verdiano, encontramos no artigo de Fortes uma análise etnográfica dos efeitos do passado colonial, sobretudo de sua dimensão moral, nos valores e nas práticas contemporâneos relativos ao universo doméstico. Fortes argumenta que as mulheres em Cabo Verde enfrentam hoje um duplo desafio na constituição de suas famílias. Primeiro, elas precisam lidar com um contexto marcado por múltiplos constrangimentos, que envolvem a carência de recursos materiais, os impactos do intenso fluxo migratório no país 
e a violência baseada no gênero. Em outro plano, precisam lidar com os reflexos atuais de uma moralidade colonial que procurava balizar as relaçóes no interior das famílias. A noção de uma "família saudável”, nuclear, monogâmica e patriarcal — herdada do colonialismo e reproduzida pelas instituiçóes que determinam hoje as políticas públicas em Cabo Verde - precisa ser considerada por essas mulheres na construção de seus projetos pessoais, à medida que evitam os julgamentos socialmente elaborados contra as famílias ditas "em crise e desestruturadas". Navegando entre seus desejos pessoais, os discursos que consolidam um modelo ideal de família e as condições concretas de existência, essas mulheres revelam um cotidiano muito mais dinâmico, flexível e ambíguo a contextualizar os projetos de vida familiar.

Deslocando rumo ao continente e focalizando os casos dos gigantes do império colonial português, temos duas contribuiçôes sobre Angola e Moçambique. Abrantes analisa discursos que sustentaram o processo de dominação colonial em Angola na década de 1950. A autora examina essa prática discursiva, que chama de saber colonial, com base em narrativas construídas no contexto de uma formação especializada oferecida em Lisboa para os administradores coloniais. Abrantes mostra como os textos dos administradores coloniais, escritos durante esse processo formativo, representam os africanos como trabalhadores que não correspondiam a um ideal de indígena. Além disso, tais narrativas ampliam as classificaçóes sociais que a administração colonial considerava problemáticas, na medida em que não ficavam restritas à questão indígena. Por fim, os textos produzidos nos cursos de formação em Lisboa compartilham a ideia de um Estado imaginado, que se via como responsável pela administração de populaçôes dependentes e merecedoras de seus cuidados. A contribuição de Abrantes apresenta os fundamentos das diferenciaçóes entre "nós" e "eles" no período colonial tardio, seus efeitos assimiladores e homogeneizadores da população africana, e os pressupostos bem como as condiçôes de possibilidade para a continuidade, transformada, do exercício da vocação imperial.

Farré argumenta que, independentemente do regime político (colonial ou pós-colonial), a exclusão social tem sido uma característica constante da vida moçambicana. O autor examina as categorias sociais desenvolvidas durante o processo de dominação colonial português no início do século $\mathrm{XX}$, mas continuadas com o colapso do império colonial, permanecendo atuantes, apesar de transformadas, no presente pós-colonial. Farré observa, com um agudo e criterioso olhar, os diversos percursos e as transformaçóes sofridas pelas categorias "indígena”, "civilizado", “assimilado" e "régulo" na cultura política de Moçambique, analisando debates e projetos políticos elaborados por 
moçambicanos de vários estratos sociais em diferentes momentos da história do país. A perversa permanência — transformada e disfarçada — da ênfase na diferença, sob a forma sociológica da exclusão social, é revelada pela perspectiva crítica do autor.

Por fim, temos a contribuição de Tomàs, que olha com cuidado analítico para a perspectiva que o governo colonial francês elaborou sobre as autoridades religiosas tradicionais e a religiáo tradicional dos grupos joola do Baixo Casamansa, no Senegal. Tomàs mostra que, desde o início da colonização da região, no fim do século XIX, os franceses não conseguiram elaborar um olhar monolítico e único sobre a cultura joola. Enquanto alguns representantes da administração francesa viam os joolas como um povo selvagem, que devia ser civilizado o mais completa e rapidamente possível, outros agentes coloniais argumentavam que eles eram um povo inteligente e permeável às novidades trazidas pela dominação colonial. A heterogeneidade da percepção francesa sobre os joolas da Casamansa revelada pelo autor encontra eco imediato nas contribuiçóes de Castro e Gargallo sobre a Namíbia, mas também, de modo mais difuso, nos restantes trabalhos deste dossiê, que mostra que, apesar da violência, da força e da busca de supressão ou controle da diferença, a experiência colonial sempre foi prenhe de contradição, disputa e luta pela conformação dos corações.

Recebido em 27/09/2015.

Aceito em 20/11/2015.

Wilson Trajano Filho é professor do Departamento de Antropologia da Universidade de Brasília e pesquisador associado ao Max Planck Institute for Social Anthropology em Halle-Saale. Antropologia da África e do colonialismo, sociedades crioulas, e crioulização e cultura popular são suas principais áreas de pesquisa. Contato: wilson.trajanofilho@gmail.com

Juliana Braz Dias é professora do Departamento de Antropologia da Universidade de Brasília e pesquisadora associada na Universidade de Pretória. Possui experiência de pesquisa sobre culturas populares africanas, com trabalho de campo em Cabo Verde e África do Sul. Organizou, com Andréa Lobo, a coletânea África em movimento (ABA Publicaçôes, 2012). Contato: jbrazdias@ hotmail.com 


\section{Referências bibliográficas}

BRAZ DIAS, Juliana. 2002. "Língua e poder: transcrevendo a questão nacional". Mana, 8(1):7-27.

2012. "Música cabo-verdiana, música do mundo". In: Juliana Braz Dias \& Andréa de Souza Lobo (orgs.), África em movimento. Brasília: ABA Publicaçóes. pp. 85-102.

CARVALHO, Clara \& PINA CABRAL, João (orgs.). 2004. A persistência da história: passado e contemporaneidade em África. Lisboa: Imprensa de Ciências Sociais.

COMAROFF, John L. \& COMAROFF, Jean. 1991. Of revelation and revolution: Christianity, colonialism and consciousness in South Africa. Chicago: The University of Chicago Press. v. 1.

1997. Of revelation and revolution: the dialectics of modernity on a South African frontier. Chicago: The University of Chicago Press. v. 2.

COOPER, Frederick \& STOLER, Ann Laura (eds.). 1997a. Tensions of empire: colonial cultures in a bourgeois world. Berkeley/Los Angeles/London: University of California Press.

1997b. "Between metropole and colony: rethinking a research agenda". In: Frederick Cooper \& Ann Laura Stoler (eds.), Tensions of empire: colonial cultures in a bourgeois world. Berkeley/Los Angeles/London: University of California Press. pp. 1-56.

DURKHEIM, Émile \& MAUSS, Marcel. 1981. "Algumas formas primitivas de classificação". In: José Albertino Rodrigues (org.), Émile Durkheim: sociologia. São Paulo: Ática. Coleção Grandes Cientistas Sociais. pp. 183-203. Publicado originalmente em 1903.

ERLMANN, Veit. 1999. Music, modernity and the global imagination. Oxford: Oxford University Press.

FABIAN, Johannes. 1971. Jamaa: a charismatic movement in Katanga. Evanston: Northwestern University Press.

FRITH, Simon. 2000. "The discourse of world music". In: Georgina Born \& David Hesmondhalgh (orgs.), Western music and its others: difference, representation, and appropriation in music. Berkeley: University of California Press. pp. 305-322.

PRICE, Sally. 2000. Arte primitiva em centros civilizados. Rio de Janeiro: UFRJ. 
RANGER, Terence. 1968a. "Connexions between 'primary resistance' movements and modern mass nationalism in East and Central Africa" (part I). The Journal of African History, 9(3):437-453.

. 1968b. "Connexions between 'primary resistance' movements and modern mass nationalism in East and Central Africa" (part II). The Journal of African History, 9(4):631-641.

STOKES, Martin. 2004. "Music and the global order". Annual Review of Anthropology, 33:47-72.

TAYLOR, Timothy D. 1997. Global pop: world music, world markets. Nova York: Routledge.

TRAJANO FILHO, Wilson. 2004. "A constituição de um olhar fragilizado: notas sobre o colonialismo português em África”. In: Clara Carvalho \& João de Pina Cabral (orgs.), A persistência da história: passado e contemporaneidade em África. Lisboa: Imprensa de Ciências Sociais. pp. 21-59.

. 2006. "Por uma etnografia da resistência: o caso das tabancas de Cabo Verde". Série Antropologia, 408:1-36.

WILLIAMS, Raymond. 1979. Marxismo e literatura. Rio de Janeiro: Zahar.

WOOLF, Virginia. 2015. The Waves. Org. por David Bradshaw. Oxford: Oxford University Press. 


\section{Resumo}

O colonialismo foi mais do que um sistema de exploração econômica e dominação política, e pode mesmo ser entendido como um modo de percepção do mundo. Produziu formas de enquadramento da vida social e criou relaçóes fundadas em forças hegemônicas - sempre em tensão construtiva com imagens contrahegemônicas. Este artigo discute as categorias geradas pelo colonialismo. Oferece, igualmente, uma introdução aos trabalhos reunidos neste dossiê, cujo enfoque recai sobre as experiências coloniais em África. Este conjunto de reflexóes visa à análise dos mapas mentais elaborados no intuito de orientar a navegaçáo na paisagem colonial africana. Busca ainda fornecer subsídios para uma reflexão sobre o que restou desse modo de enquadrar o mundo depois das descolonizaçóes.

Palavras-chave: pós-colonial; África; sistemas classificatórios; hegemonia.

\section{Abstract}

Colonialism was more than a system of economic exploitation and political domination, and it may be seen as a mode of world-perception. It produced frameworks for the constitution of social life and created relations based on hegemonic forces - always in tension with constructive counter-hegemonic images. This article discusses the categories generated by colonialism. It also offers an introduction to the other articles gathered in this special issue, whose focus is on colonial experiences in Africa. This work addresses the mental maps drawn up in order to guide the navigation in African colonial landscape. It also seeks to provide subsidies for a reflection on what is left of this way of framing the world after decolonization.

Keywords: colonialism; postcolonial; Africa; classificatory systems; hegemony. 